\title{
Helping Junior High School Student to Learn Fibonacci Sequence with Video-Based Learning
}

\author{
https://doi.org/10.3991/ijim.v15i11.23097 \\ Tommy Tanu Wijaya, Li Li \\ Guangxi Normal University, Guilin, China \\ Neni Hermita ${ }^{\bowtie}$, Zetra Hainul Putra, Jesi Alexander Alim \\ Universitas Riau, Pekanbaru, Indonesia \\ Neni.hermita@lecturer.unri.ac.id
}

\begin{abstract}
In this 21 st century, teachers need to make teaching and learning activities conducive and fun to improve students' learning interests. According to preliminary studies, the Fibonacci sequence is one of the materials that are difficult for Junior High school students to master. Therefore, this study aims to design instructional material videos on the Fibonacci sequence using Hawgent and Camtasia studio. The research and development $(\mathrm{RnD})$ method was used to research at the Guangxi Normal University, China, using the 4D model comprising Define, Design, Development, and Disseminate. From February to April 2020, the authors developed instructional materials using engaging animations that are easy for students to understand. This study showed that the instructional materials were valid with a score of $83.33,79.17$, and 87.50 from the instructional material expert, media expert, and lecturer, respectively. These scores indicated that the instructional materials in video form are valid and can be sent to schools to help students understand the Fibonacci sequence. However, the implementation stage and the effect on students' mathematical abilities are still needed.
\end{abstract}

Keywords - Fibonacci, Junior High School student, Video-Based Learning, Geometry Sequence

\section{Introduction}

The use of technology in mathematics teaching is not new because both are inseparable. Technology helps students understand a mathematical concept, and it also significantly improves their mathematical ability [1]-[6]. Its use also makes them more active in class [7], [8], thereby improving their ability to ask unique and creative questions. There has been much research in China on using technology in teaching and learning activities [4], [9]-[11]. However, this research was carried out to determine the significance associate with the use of technology in mathematics learning [12], [13]. University students in China and other countries have used much software to develop learning media for mathematics [14], [15]. Indonesia has also 
focused on developing a learning media for mathematics using technology-based learning media in all levels of education, from primary schools to universities [16], [17]. Most universities in Indonesia are also developing various technology-based learning media to help teachers and students explain and understand mathematics concepts. Martin Bernard, a lecturer from IKIP Siliwangi, Bandung, has developed many technology-based learning media to help teachers and students during mathematics lessons [18]-[21]. Many studies develop instructional materials; however, none has developed interesting instructional materials on the Fibonacci sequence and daily life and its history and figure.

Fibonacci is a series of numbers with each obtained from 2 numbers before them. Leonardo da Pisa first introduced Fibonacci numbers in the 13th century [22]. It is used for numerous purposes, such as predicting the price change of a product in economics. Fibonacci numbers are also used in our everyday life, and their sequence also has a close relationship with the arithmetic sequence taught in 11th grade. Furthermore, it is one of the introductory university courses [23], [24]. An arithmetic sequence is also one of the concepts tested in the Indonesian national exam. Unfortunately, irrespective of the importance of Fibonacci and arithmetic sequence, there are essential and exciting instructional materials to help students. Therefore, the authors decided to develop instructional materials in video form.

The aims of this study are as follows:

1. Determining the best way for teachers to explain the Fibonacci sequence to students (define stage).

2. Making videos that contained instructional materials on Fibonacci sequence using Hawgent and Camtasia Studio (Design stage)

3. Validating the videos by a media expert, an instructional material expert, and a lecturer.

\section{$2 \quad$ Method}

The development of learning media used the 4D method comprising Define, Design, Develop and Disseminate [25]. Firstly, the authors carried out a preliminary study to determine the difficulties and attitudes of Junior High School students' when learning arithmetic sequence. The learning video was developed in Guangxi Normal University, China, with data obtained from 51 first-year students. Secondly, a learning video was made according to the initial observation result using Hawgent dynamic mathematics software, Microsoft PowerPoint, and Camtasia studio. The video was first designed using Hawgent then Camtasia studio before it was validated by material and media experts. The validators are experts in their field, which includes three from China and three from Indonesia. This research only focuses on making the learning video process is conducted separately to ensure its quality.

When validating the learning video on Fibonacci, the authors gave out questionnaires to validators, as shown in Table 1. 
Table 1. Validation criteria

\begin{tabular}{|c|l|}
\hline Score & \multicolumn{1}{|c|}{ Explanation } \\
\hline 1 & If the validator feels the learning video is not good \\
\hline 2 & If the validator feels the learning video is not so good \\
\hline 3 & If the validator feels the learning video is pretty good \\
\hline 4 & If the validator feels the learning video is good \\
\hline
\end{tabular}

The questionnaire result was analyzed using the four-degree percentage analysis technique. The data analysis formula is as follows.

$$
\mathrm{Pi}=\left(\frac{x i}{y i}\right) x 100 \%
$$

Where:

Pi: A percentage value

$\mathrm{Xi}$ : Accumulation of validation result

Yi: Maximum score of the validation result

The percentage result was analyzed further using the validation category. When the percentage score is above $70.1 \%$, as shown in Table 2 , the learning video is feasible and can be continued to the micro class stage.

Table 2. Validation criteria on the learning media [26]

\begin{tabular}{|c|l|l|}
\hline Validation range & \multicolumn{1}{|c|}{ Validation category } & \multicolumn{1}{c|}{ Explanation } \\
\hline $85,01 \% \leq \mathrm{v} \leq 100 \%$ & Valid & It can be used without any revision \\
\hline $70,1 \% \leq \mathrm{qv} \leq 85,00 \%$ & Quite Valid & It can be used with a little revision \\
\hline $50,1 \% \leq 1 \mathrm{v} \leq 70,00 \%$ & Less Valid & It can be used with much revision \\
\hline $00,00 \% \leq \mathrm{nv} \leq 50,00 \%$ & Not Valid & It cannot be use \\
\hline
\end{tabular}

\section{Result}

\subsection{Define stage}

The authors analyzed the importance of Fibonacci in school. They realized that the Fibonacci sequence is a part of arithmetic taught in 11th grade and introductory university courses. Ouellette [27] stated a correlation between studying the Fibonacci sequence and increasing problem-solving ability.

Furthermore, based on the school's observation, the authors found that students were not familiar with the Fibonacci sequence despite studying a similar topic known as an arithmetic sequence. When the authors asked students about Fibonacci, most of those in Junior High School had no idea, with only a few aware of its interconnection with arithmetic sequence. According to preliminary studies, students need to know the history of mathematical concepts and understand why it is unique and exciting. Furthermore, teachers directly teach students the concept of sequence without a proper introduction. This makes it difficult for students to understand, with those in 
Junior High school only remember the formula and guess the sequence. Therefore, they feel the learning sequence is boring.

The above problem encouraged the authors to use technology to help Junior High students and teachers develop a unique learning media that introduces the history of mathematics to achieve deep and proper learning.

After discussing with Professor Tang Jianlan from Guangxi Normal University, China, the authors designed a learning video on arithmetic sequence to explain its relationship with the Fibonacci sequence. This learning video was designed using three software: Hawgent Dynamic Mathematics Software, Microsoft PowerPoint, and Camtasia Studio.

In the design stage, the authors carried out concept and curriculum analysis to determine the importance of the basic concept of sequence and the relationship between Fibonacci and arithmetic sequence for high school and university students. After analyzing the concept and curriculum, students need to master the sequence as tested in the Indonesian National Examination.

\subsection{Design stage}

Hawgent dynamic mathematics software was used to make a learning media on an arithmetic sequence. Its latest version 3.0 design is user-friendly as it enables users to change pictures from 2D format to 3D using a button. This software helps teachers to create exciting learning media using pictures easily.

Furthermore, it enables the easy conversion of animations into pictures savable in Microsoft PowerPoint. The authors used PowerPoint to explain the arithmetic sequence and connected it with the history and culture of Fibonacci. The history of Fibonacci is obtainable from Google and Wikipedia.

At the beginning of the learning video, the authors introduced Fibonacci (figure 1), its relationship with mathematics, and the Fibonacci sequence. Before moving to the main topic, the video learning introduces the relationship between arithmetic and Fibonacci sequence. Students were also introduced to the mathematics' historical figures to increase their learning interest in mathematics, associated with numbers and formulas and its own culture and history.

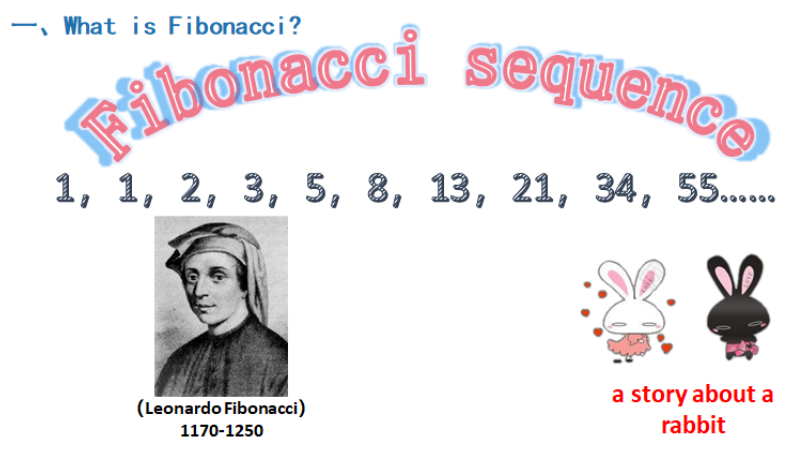

Fig. 1. History introduction on Fibonacci 
After introducing students to Fibonacci and its relationship with mathematics, the video explains its sequence, as shown in Figure 2. The authors used rabbit breeding as a context to explain the Fibonacci sequence to students. The cute rabbit animation grabbed their attention and made them understand the initial topic better [28]. This is also in line with preliminary research, which stated that contextual problems improve students' mathematical ability [29], [30].

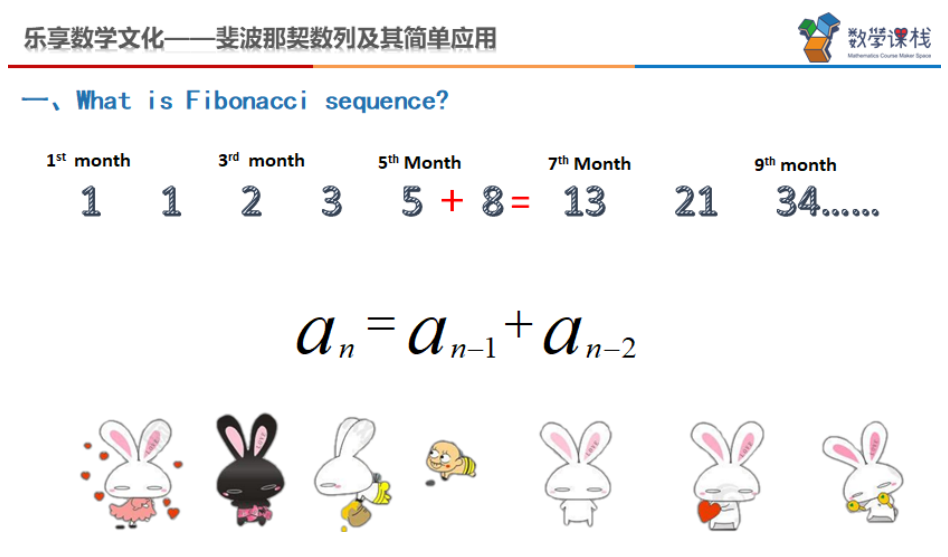

Fig. 2. Formula proving of the Fibonacci sequence using rabbit animation

The learning video also explains that students find many things connected to the Fibonacci sequence in everyday activity. For instance, the authors used flowers (Figures 3) and fruits (figures 4) to cite instances in this research. It guides students to understand that the Fibonacci sequence is present in their daily lives and understand the importance of mastering basic mathematics concepts.

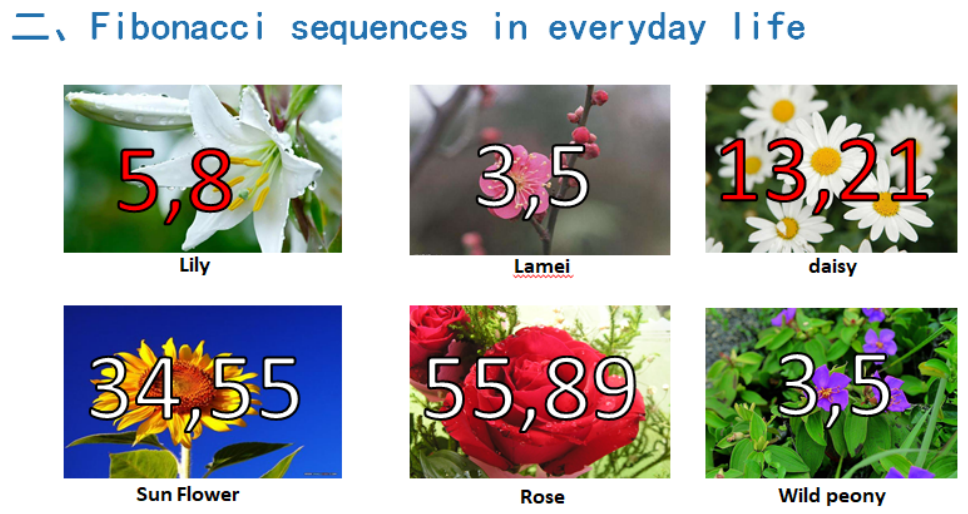

Fig. 3. Fibonacci sequence in flowers 


\section{Fibonacci sequences on fruits}

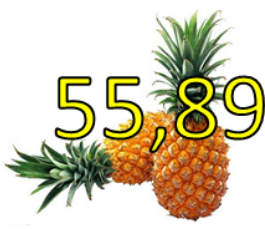

pineapples

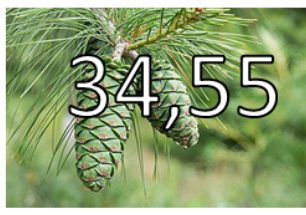

Pine cones

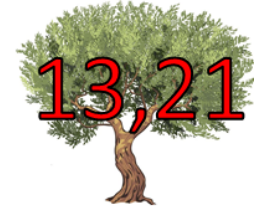

Branches

Fig. 4. Fibonacci sequence in fruits

\subsection{Development stage}

The learning video was validated by two material experts, two lecturers, and two media experts. Of the six validators, three were from Indonesia and the remaining three from China. Furthermore, the average validation score from the material expert is $83.33 \%$. The media expert's scores were $75 \%$ and $83.33 \%$, thereby leading to an average of $79.17 \%$. The lectures' scores were $91.66 \%$ and $83.33 \%$; hence, an average of $87.50 \%$ was obtained. Based on the validation score given by material, media experts, and lecturers, it was concluded that the learning video is valid and can be tested on a small scale. The graphic on the validation score is shown in figure 5.

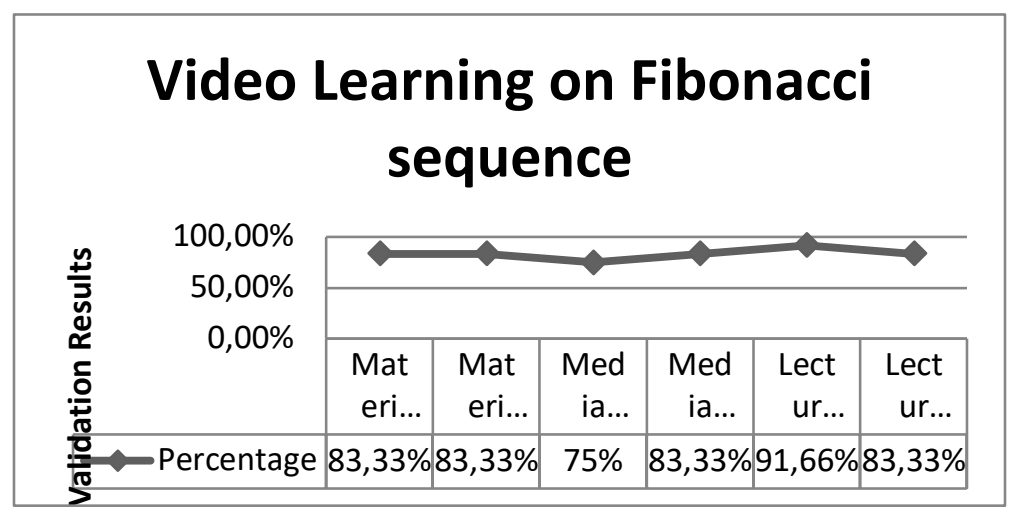

Fig. 5. Results of the five validators' assessment

As previously discussed, this research only focuses on developing the product from the define to product validation stage. Subsequent research needs to implement the learning media to high school and university students to analyze their learning ability, outcome, interest, and other mathematical abilities. 


\section{Conclusion}

In conclusion, learning videos tend to increase students' learning interest in the Fibonacci sequence. The learning video on Fibonacci made using Hawgent with a duration of 6 minutes and 36 seconds has been validated with inputs obtained from material and media experts. The validation results from the material expert, the media expert, and the lecturer, showed that the instructional materials in video form could be implemented in schools to help students understand the Fibonacci sequence. In this study, the authors only carried out the preliminary analysis, media design, and validation. Further studies need to be carried out to determine the effect of learning videos on the students' mathematical ability.

\section{Acknowledgement}

The authors are grateful to the Ministry of Research and Technology/National Research and Innovation Agency Indonesia (RISTEKBRIN) for supporting this study under the grand of DRPM 2021 (498/UN.19.5.1.3/PT.01.03/2021).

\section{$6 \quad$ References}

[1] S. Papadakis, M. Kalogiannakis, and N. Zaranis, "Teaching mathematics with mobile devices and the Realistic Mathematical Education (RME) approach in kindergarten. Advances in Mobile Learning Educational Research, 1(1), 5-18, 2021. https://doi.org/10.25082/AMLER.2021.01.002. https://doi.org/10.4236/ce.2013.47a1001

[2] S. Papadakis, M. Kalogiannakis, and N. Zaranis, "The effectiveness of computer and tablet assisted intervention in early childhood students' understanding of numbers." An Empir. Study Conduct. Greece. Educ. Inf. Technol., vol. 23, no. 5, 2018. https://doi.org/10. 1007/s10639-018-9693-7

[3] S. Papadakis, M. Kalogiannakis, and N. Zaranis, "Comparing tablets and PCs in teaching mathematics: An attempt to improve mathematics competence in early childhood education,” Presch. Prim. Educ., vol. 4, no. 2, pp. 241-253, 2016. https://doi.org/10. $\underline{12681 / \text { ppej.8779 }}$

[4] X. Zhang, Y. Zhou, and T. T. Wijaya, "Hawgent Dynamic Mathematics Software to Teach Line and Angle," JNPM (Jurnal Nas. Pendidik. Mat., vol. 4, no. 2, pp. 237-247, 2020. https://doi.org/10.33603/jnpm.v4i2.3473

[5] N. Hermita, H. S. Ningsih, J. A. Alim, M. Alpusari, Z. H. Putra, and T. T. Wijaya, "Developing Science Comics for Elementary School Students on Animal Diversity," Solid State Technol., vol. 63, no. 1s, 2020.

[6] S. Tan, T. T. Wijaya, L. Zou, and N. Hermita, "Proving the Formula for the Area of a Circle using Hawgent Dynamic Mathematics Software," J. Phys. Conf. Ser., vol. 1655, no. 1, p. 012052, 2020. https://doi.org/10.1088/1742-6596/1655/1/012052

[7] T. T. Wijaya, T. Jianlan, and A. Purnama, "Developing an Interactive Mathematical Learning Media Based on the TPACK Framework Using the Hawgent Dynamic Mathematics Software," in Emerging Technologies in Computing, 2020, pp. 318-328. https://doi.org/10.1007/978-3-030-60036-5 24 
[8] S. Papadakis, "Robots and Robotics Kits for Early Childhood and First School Age.," Int. J. Interact. Mob. Technol., vol. 14, no. 18, pp. 34-56, 2020. https://doi.org/10.3991/ ijim.v14i18.16631

[9] T. T. Wijaya, "How Chinese students learn mathematics during the coronavirus pandemic," Int. J. Educ. Res. Innov., vol. 15, pp. 1-16, 2021.

[10] T. T. Wijaya, Z. Ying, and A. Purnama, "Using Hawgent dynamic mathematics software in teaching trigonometry," Int. J. Emerg. Technol. Learn., vol. 15, no. 10, 2020. https://doi.org/10.3991/ijet.v15i10.13099

[11] H. Wiranota and T. T. Wijaya, "The international students ' perception towards online learning using the Tencent meeting during covid-19 outbreak The international students ' perception towards online learning using the Tencent meeting during the covid-19 outbreak," J. Phys. Conf. Ser., vol. 1823, 2021. https://doi.org/10.1088/1742$\underline{6596 / 1823 / 1 / 012011}$

[12] W. Aixia, Z. Ying, and T. T. Wijaya, "The current situation and prospect of study quality evaluation research in china in the last 10 years," EDUKATIF J. ILMU Pendidik., vol. 2, no. 1, pp. 101-112, 2020. https://doi.org/10.31004/edukatif.v2i1.83

[13] L. Cunhua, Z. Ying, O. Qunzhuang, and T. T. Wijaya, "Mathematics course design based on six questions cognitive theory using hawgent dynamic mathematic," J. Educ., vol. 02, no. 01, pp. 36-44, 2019.

[14] T. T. Wijaya, Z. Ying, and L. Suan, "Gender and Self-regulated Learning During COVID19 Pandemic in Indonesia," J. basicedu, vol. 4, no. 3, pp. 725-732, 2020. https://doi.org/10.31004/basicedu.v4i3.422

[15] L. Suan, Z. Ying, and T. T. Wijaya, "Using hawgent dynamic mathematics software in teaching arithmetic operation,” Int. J. Educ. Learn., vol. 2, no. 1, pp. 25-31, 2020.

[16] S. Chotimah, T. T. Wijaya, E. Aprianti, P. Akbar, and M. Bernard, "Increasing primary school students' reasoning ability on the topic of plane geometry by using hawgent dynamic mathematics software," J. Phys. Conf. Ser., vol. 1657, no. 1, p. 012009, 2020. https://doi.org/10.1088/1742-6596/1657/1/012009

[17] T. T. Wijaya, Z. Zulfah, A. Hidayat, P. Akbar, W. Arianti, and I. Asyura, "Using VBA for Microsoft excel based on 6-questions cognitive theory in teaching fraction," J. Phys. Conf. Ser., vol. 1657, no. 1, p. 012078, 2020. https://doi.org/10. 1088/1742-6596/1657/1/012078

[18] T. T. Wijaya, Z. Ying, S. Chotimah, M. Bernard, Z. Zulfah, and A. Astuti, "Hawgent dynamic mathematic software as mathematics learning media for teaching quadratic functions," J. Phys. Conf. Ser., vol. 1592, no. 1, 2020. https://doi.org/10. 1088/1742$\underline{6596 / 1592 / 1 / 012079}$

[19] M. Bernard and S. Chotimah, "Improve student mathematical reasoning ability with openended approach using VBA for PowerPoint," AIP Conf. Proc., vol. 2014, no. September 2018. https://doi.org/10.1063/1.5054417

[20] I. F. Al-Mashaqbeh, "IPad in elementary school math learning setting," Int. J. Emerg. Technol. Learn., vol. 11, no. 2, pp. 48-52, 2016. https://doi.org/10.3991/ijet. v11i02.5053

[21] M. Mushipe and U. I. Ogbonnaya, "Geogebra and Grade 9 learners' achievement in linear functions," Int. J. Emerg. Technol. Learn., vol. 14, no. 8, pp. 206-219, 2019. https://doi.org/10.3991/ijet.v14i08.9581

[22] D. Hoffman and C. R. Johnson, Mathematics and Visualization in Art and Education. springer-verlag berlin, 2002.

[23] Y. Lin, Y. Zhou, S. Wang, and T. T. Wijaya, "Lesson design of geometric sequences based on the 6-question cognitive theory," J. Educ., vol. 02, no. 04, pp. 313-322, 2020. https://doi.org/10.31004/joe.v2i4.325 
[24] M. Sangeetha and S. Malathi, "Identifying AEAP ALAP sequences for optimization using dependency structures,” Int. J. Sci. Technol. Res., vol. 9, no. 2, pp. 1-4, 2020.

[25] A. M. Ilmi, Sukarmin, and W. Sunarno, "Development of TPACK based-physics learning media to improve HOTS and scientific attitude," J. Phys. Conf. Ser., vol. 1440, no. 1, 2020. https://doi.org/10.1088/1742-6596/1440/1/012049

[26] D. Alvionita, W. Subchan, and M. Iqbal, "The development of ecosystem education game based on Baluran National Park for senior high school," J. Phys. Conf. Ser., vol. 1465, no. 1, 2020. https://doi.org/10.1088/1742-6596/1465/1/012039

[27] H. Ouellette, “Fibonacci xz' s Triangle: A Vehicle for Problem Solving," Sch. Sci. Math., vol. 79, no. 3, pp. 248-254, 1979.

[28] S. Chotimah, M. Bernard, and S. M. Wulandari, "Contextual approach using VBA learning media to improve students' mathematical displacement and disposition ability," J. Phys. Conf. Ser., vol. 948, no. 1, 2018. https://doi.org/10.1088/1742-6596/948/1/012025

[29] M. Bernard, P. Akbar, A. Ansori, and G. Filiestianto, "Improve the ability of understanding mathematics and confidence of elementary school students with a contextual approach using VBA learning media for Microsoft Excel," J. Phys. Conf. Ser., vol. 1318, no. 1, 2019. https://doi.org/10.1088/1742-6596/1318/1/012035

[30] W. N. Mentari and H. Syarifuddin, "Improving student engagement by mathematics learning based on contextual teaching and learning," J. Phys. Conf. Ser., vol. 1554, p. 012003, 2020. https://doi.org/10.1088/1742-6596/1554/1/012003

\section{$7 \quad$ Authors}

Tommy Tanu Wijaya has a master's degree in mathematics and statistics from Guangxi Normal University, Guilin, China. Address: Guangxi Normal University, Yanshan no. 1, Guilin, China. Email: tanuwijayat@gmail.com

Li Li is a student at Guangxi Normal University Guilin, China. Address: Guangxi Normal University, Yanshan no. 1, Guilin, China. Email: 1551586972@qq.com

Neni Hermita is a Lecturer at Universitas Riau, Indonesia. Email: neni.hermita @)lecturer.Unri.ac.id

Zetra Hainul Putra is a Lecturer at Universitas Riau, Indonesia. Email: zetra.hainul.putra@lecturer.unri.ac.id

Jesi Alexander Alim is a Lecturer at Universitas Riau, Indonesia. Email: jesi. alexander@lecturer.unri.ac.id

Article submitted 2021-03-23. Resubmitted 2021-04-30. Final acceptance 2021-04-30. Final version published as submitted by the authors. 